\title{
The grounds for the modification of membranes with the help of quantum mechanical calculation method
}

\author{
Mykola Nechytailo $^{1}$, Olena Nahorna ${ }^{1, *}$, and Olena Nesterova $^{1}$ \\ ${ }^{1}$ Higher Education State Institution "Prydniprovsk State Academy of Civil Engineering and \\ Architecture", 49600, Dnipro, Chernyshevskoho Str., 24a, Ukraine
}

\begin{abstract}
In the process of water purification to increase the reflective capacity of ultrafiltration membranes, their surface modification is applied with aluminium oxychloride and polyhexamethylene guanidine hydrochloride are used. This enables to extract organic contaminations at $90 \%$ level, not less their salt balance. To estimate the reaction capacity, the method of calculation of energetic parameters and structural characteristics with the help of chemical analysis quanta is applied. For the analysis, the semiempirical method of modified neglect of diatomic overlapping is used. The prospective estimation of gel layer formation on the membrane surface is made. The method of molecular mechanics is applied in quantumchemical calculations for each substance and the material of the membrane. While analyzing the interaction between the material of the membrane and membrane-forming supplement, the charges on molecules' atoms, the determination of energetic levels of the lower vacant and upper filled molecular orbitals and energetic gap are estimated. It was proved that aluminium oxychloride precipitates on the membrane surface due to Van der Waltz forces, and the inoculation of polyhexamethylene guanidine occurs at fiber functionalization through the formation of hydrogen type of bond between the groups $\mathrm{C} \equiv \mathrm{N}$ polymer and $=\mathrm{N}-\mathrm{H}$ group. Scientific substantiation of membrane modification was obtained.
\end{abstract}

\section{Introduction}

Mining industry is one of the serious pollutants of surface watercourse. While processing and extracting mineral resources, lots of water is used, as a result, there is wastewater with pollutant concentrations, which exceed MPC (maximum permissible concentration) [1, 2]. Technological stages of water purification allow for contamination reduction in mining and processing industries by $96 \%$. However, more complex organic contaminants such as humin and fulvic acids are disposed into watercourses. Sharp deterioration of water quality in surface sources leads to the necessity of search for reliable methods of water processing which enable to decrease the pollution concentration to the necessary parameters. The elaboration, together with the improvement of methods of surface water decontamination

${ }^{*}$ Corresponding author: ek_n@i.ua 
with the help of membrane technologies, is one of the priorities in the sphere of municipal and industrial water preparation.

The freshwater surface sources of water supply in Ukraine and, in particular, the main waterway the river Dnipro, have a high level of contamination with organic substances. The work [1] represents a developed technology of ultrafiltration with dynamic awash layer. The efficacy of work in removing organic substances has been estimated according to the index of permanganate oxidizability and is more than $90 \%$.

While carrying out experimental researches, it is ascertained that the best reagents for the modification of ultrafiltration membranes are aluminum oxychloride and polyhexamethyl guanidine hydrochloride (PGMG-GC). The usage of PGMG-GC enables to give bactericidal inoculation on the surface of the membrane and thus, to exclude the necessity of usage of biocide reagents at periodic rinsing of membranes with a modified dynamic layer [2].

However, it is necessary to ground a purposeful selection of modifiers, which on the first stage includes theoretic basis and description of the mechanism of physicochemical modification by the way of reaction ability, particularly, the determination of active centers of both membrane surface and components-modifiers [3]. This grounding can be performed using the methods for predicting quantum chemical reactions.

The active centers, through which functualization (modification) can occur, are often reaction-capable functional groups, while adsorptive powers which cause chemical strength of interaction, and as a result, the efficiency of such modification, can differ: from ionic gravity to hydrophobic or hydrogen bonds. Thus, theoretical estimation of reaction capacity and analysis of active centers distribution on the membrane surface [4] and in the structure of components-modifiers, as well as the estimation of the formed layer stability, is an important theoretical aspect for the purposeful selection of functionalizers and the basis for the practically received results.

The aim of the research is to prove laboratory findings and scientifically substantiate the dynamic layer formation on membrane surface by means of quantum-chemical process modelling.

\section{Methods}

The prognostic estimation of reaction capacity of structural fragments is based on quantumchemically calculated thermodynamic (energetic) parameters and structural characteristics of molecules and their fragments. For them, spatial optimization, charge calculation on molecule atoms, determination of energetic layers of lower vacant $E_{(\mathrm{LVMO})}$ and upper filled molecular orbitals $E_{(\mathrm{UFMO})}$ and their difference - energetic gap $\left(\Delta E=E_{(\mathrm{UFMO})}-E_{(\mathrm{LVMO})}\right)$ are used. According to the calculated electronic charges on molecular atoms, their capacity of chemical interaction is defined, while according to the wave function of upper filled molecular orbital (UFMO) the most probable centers for coordination with metal cations are ascertained as well as the formation of the complex combination.

For quantum-chemical calculations (QCC), we used the method of molecular mechanics MM+ and semiempirical method MNDO (method of modified neglect by diatomic overlapping) at a complete optimization of molecular geometry with the help of software package. Method of modified neglect by diatomic overlapping (MNDO) is a semiempirical method of self-consistent field (SCF). It describes in a more correct way the repulsion of non-divided electronic pairs due to the calculation of all two-electron integrals containing the pairs of atom orbitals of the same atom, overlapping the atom orbitals of different atoms is ignored (the neglect of diatomic differential overlapping). The parameters depend only on the qualities of separate atoms, but not on their pair combinations. It can be applied for 
different organic molecules containing the elements from long lines 1 and 2 from the periodic table but not transition metals. It calculates electronic properties, optimized configurations, total energy and heats of formation.

The ultrafiltration membrane is a polyacrylonitrile fiber, which is a polymer of polyacrylonitrile ((-CH2-CH(CN)-)n). Theoretical definition, estimation and analysis of active centers through which physicochemical or chemical modification can occur, is one of the primary tasks for further effective selection of reagents- functionalizers [5-7]. The prognostic estimation of reaction capacity, in particular, the determination of active centers, is based on quantum-chemically calculated thermodynamic (energetic) parameters and structural characteristics of the simplest fragment- monomer of polyacrylonitrile fiber polyacrylonitrile.

\section{Results and discussion}

The results show that in case of modification of the fiber surface by reaction-capable group, through which the reaction of chemical modification is possible, is the group $-\mathrm{C} \equiv \mathrm{N}$. Atoms of nitrogen and carbon have negative charges $-0.083 \mathrm{eV}$ and $-0.111 \mathrm{eV}$, correspondingly. On them, it was also observed the distribution of energies UFMO $(-12.66308 \mathrm{eV})$ and LVMO $(1.672989 \mathrm{eV})$, which makes this group favorable for functualization due to the formation of hydrogen bond types with organic modifiers or preliminary chemical activation and further inoculation [8].

\subsection{Quantum-chemical researches of polyacrylonitrile}

Quantum-chemical calculations of energetic parameters of polyacrylonitrile - a structural unit of ultrafiltration membrane are shown in Table 1.

Table 1. Quantum-chemical calculations of energetic parameters of polyacrylonitrile - a structural unit of ultrafiltration membrane.

\begin{tabular}{|c|c|c|c|}
\hline Structural fragment & $E_{(\mathrm{UFMO})}, \mathrm{eV}$ & $E_{(\mathrm{LVMO})}, \mathrm{eV}$ & $\Delta E, \mathrm{eV}$ \\
\hline Polyacrylonitrile & -12.66308 & 1.672989 & 14.3361 \\
\hline
\end{tabular}

The results are coordinated with the literature data, where it is stated that molecules of polymer can have linked centers along the whole chain, but anyway, there is always a connection with the surface on the ends of the chain, where polar atoms are located, such as, e.g. nitrogen or oxygen, or at double bond $\mathrm{C}=\mathrm{C}$ [9-10].

Moreover, the obtained results show that inter-chain interactions (a type of molecular interaction) of dipole-dipole type between atoms in the functional group $-\mathrm{C} \equiv \mathrm{N}$, do not influence significantly the common electronic structure of this polymer material [11], which conditions the even distribution of electrostatic potential along the surface of monomer. The second important theoretical aspect is the question whether the componentsmodifiers will join the membrane (fiber) surface and substance - functionalizer or whether they will stay in mobile equilibrium when polymer molecule of modifier or inorganic modifier is kept near the surface under the influence of ionic attraction forces.

Figure 1 represents the optimized model of a monomer of polyacrylonitrile molecule. Figure 2 represents the numeration of atoms in the model of monomer of polyacrylonitrile molecule and charges on atoms. Figure 3 represents the distribution of energy UFMO and LVMO in the optimized model of monomer of polyacrylonitrile molecule. Figure 4 represents the distribution of electrostatic potential in the optimized model of monomer of 
polyacrylonitrile molecule and isosurface.
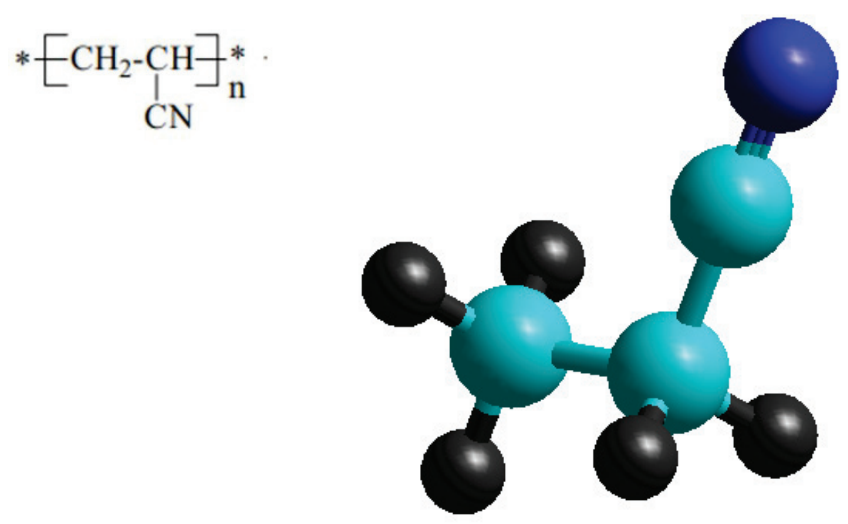

Fig. 1. Optimized model of a monomer of polyacrylonitrile molecule.

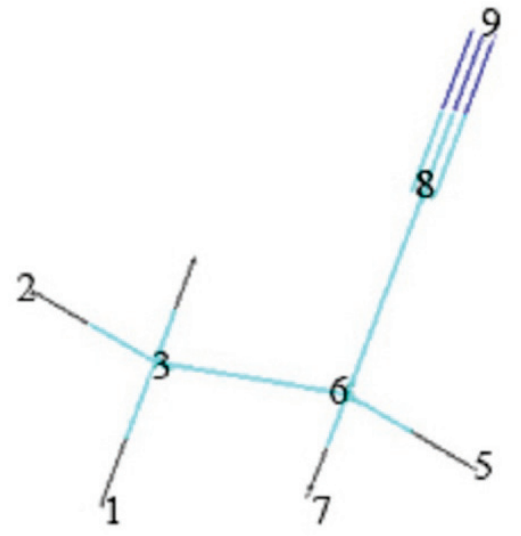

a

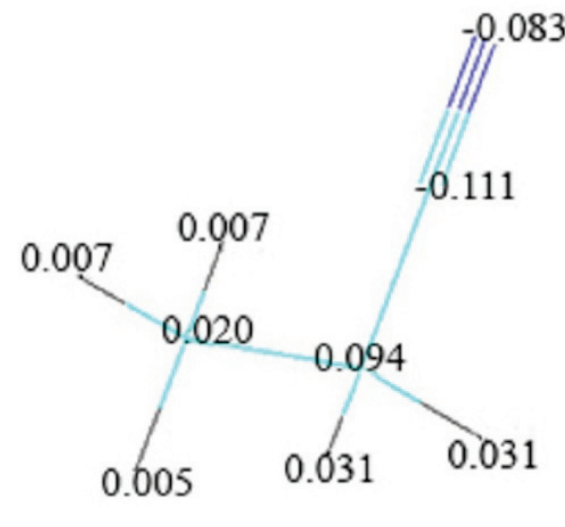

b

Fig. 2. Numeration of atoms in the model of monomer of polyacrylonitrile molecule (a); charges on atoms (b).

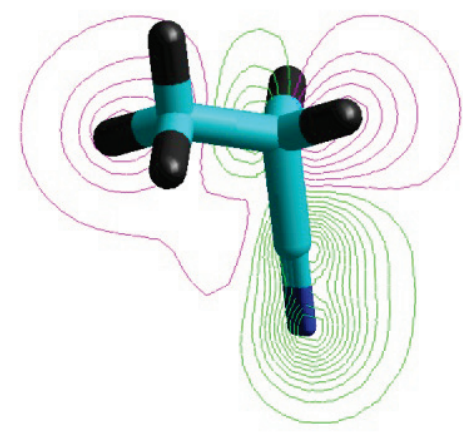

$\mathrm{a}$

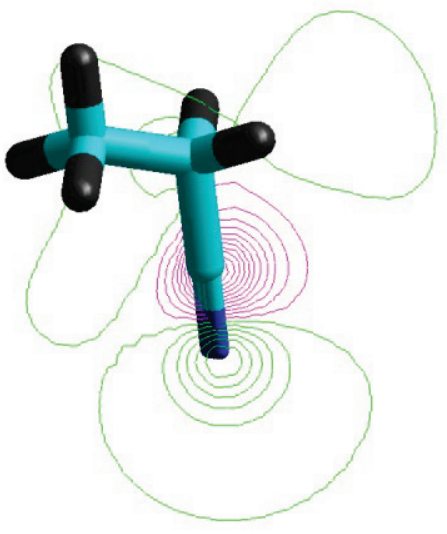

b

Fig. 3. Distribution of energy UFMO (a) and LVMO (b) in the optimized model of monomer of polyacrylonitrile molecule. 


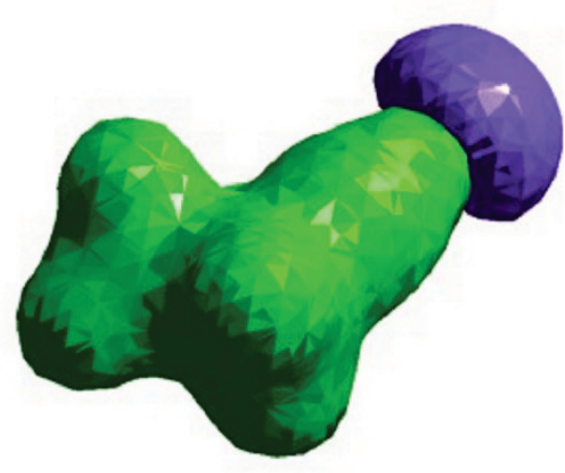

a

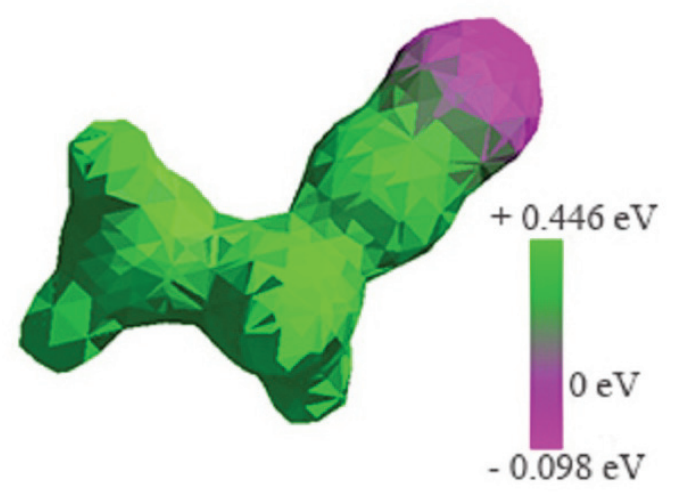

b

Fig. 4. Distribution of electrostatic potential in the optimized model of monomer of polyacrylonitrile molecule (a) and isosurface (b).

\subsection{Quantum-chemical researches of polyhexamethylene guanidine hydrochloride (PHMG-HC)}

The results of quantum-chemical calculations of structural and energetic parameters show that at the fiber modification PHMG-HC functionalization is supposed to occur through the group $=\mathrm{N}-\mathrm{H}$, which is proved by, at first, conformational position of the group, and it conditions the most negative charge of heteroatom $-0.422 \mathrm{eV}$, as well as localization (concentration) of the energy UFMO. Besides, the analysis of isosurface of molecule (3D) shows that negative electrostatic potential is mainly concentrated on $\mathrm{N}-\mathrm{H}$ группе $(-0.189 \mathrm{eV})$, as well. The reaction capacity of molecules, according to the theory, of $\mathrm{K}$. Fukui 's border orbitals is defined by the difference in energies UFMO and LVMO, which for the present modifier is $11.0446 \mathrm{eV}$.

Quantum-chemical calculations of energetic parameters of polyhexamethylene guanidine hydrochloride are given in Table 2.

Table 2. Quantum-chemical calculations of energetic parameters of polyhexamethylene guanidine hydrochloride (PHMG-HC).

\begin{tabular}{|l|c|c|c|}
\hline $\begin{array}{l}\text { Structural } \\
\text { fragment }\end{array}$ & $E_{\text {(UFM) }}, \mathrm{eV}$ & $E_{\text {(LVMO) }}, \mathrm{eV}$ & $\Delta E, \mathrm{eV}$ \\
\hline $\begin{array}{l}\text { Polyhexamethylene } \\
\text { guanidine } \\
\text { hydrochloride }\end{array}$ & -9.285146 & 1.76142 & 11.0446 \\
\hline
\end{tabular}

Figure 5 represents the monomer PHMG-HC and the optimized model of monomer of polyhexamethylene guanidine hydrochloride molecule. Figure 6 represents the symbols of atoms in the model of monomer of PHMG-HC molecule. Figure 7 represents the charges of atoms in the model of monomer of PHMG-HC molecule. Figure 8 represents the distribution of UFMO and LVMO energy in the optimized model of monomer of polyhexamethylene guanidine hydrochloride. Figure 9 represents the distribution of electrostatic potential in the optimized model of monomer of PHMG-HC molecule and isosurface. 
<smiles>CCCCCCCNC(=N)NC</smiles>

a

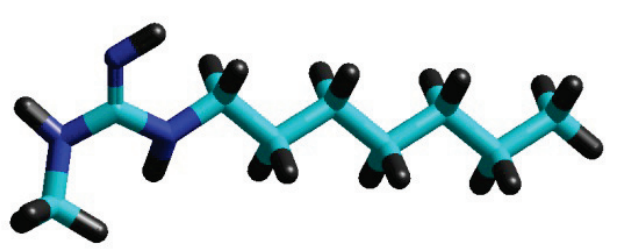

b

Fig. 5. The monomer PHMG-HC (a) and the optimized model of monomer of polyhexamethylene guanidine hydrochloride molecule (b).<smiles>CCCCCC(C)N</smiles>

a

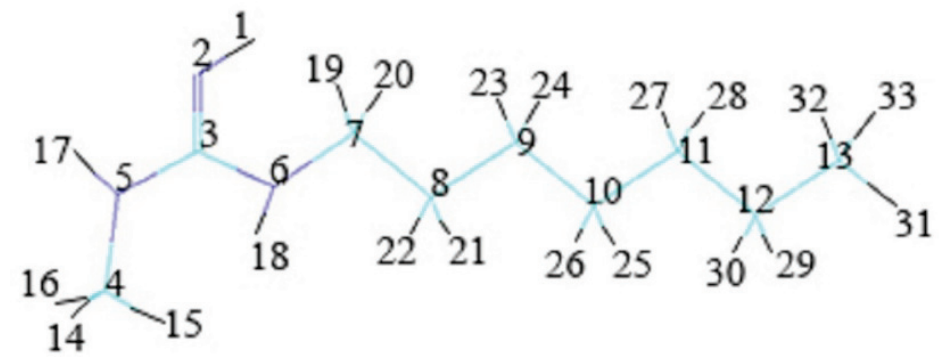

b

Fig. 6. The symbols of atoms (a) and numeration of atoms (b) in the model of monomer of PHMGHC molecule.

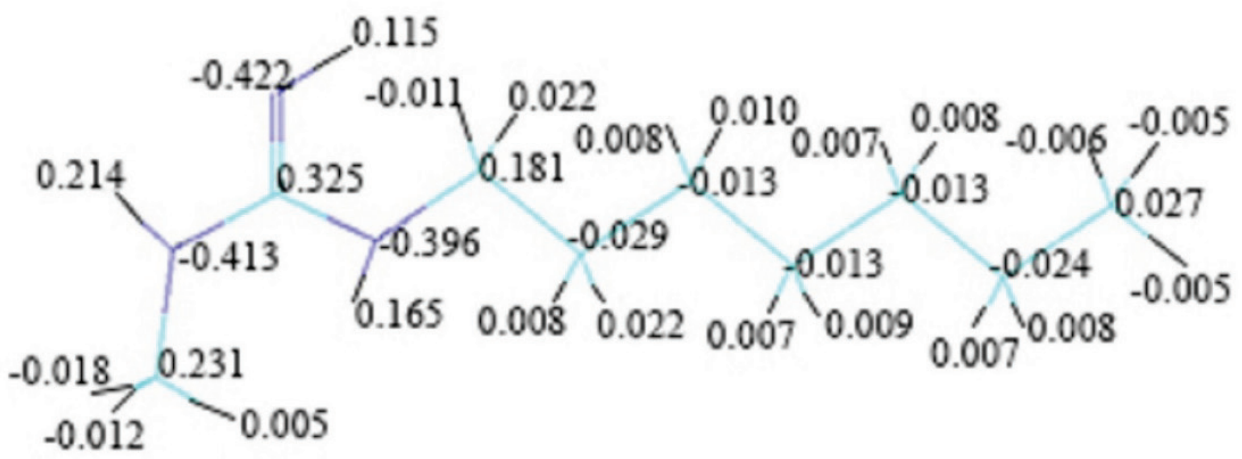

Fig. 7. Charges of atoms in the model of monomer of polyhexamethylene guanidine hydrochloride molecule (PHMG-HC). 

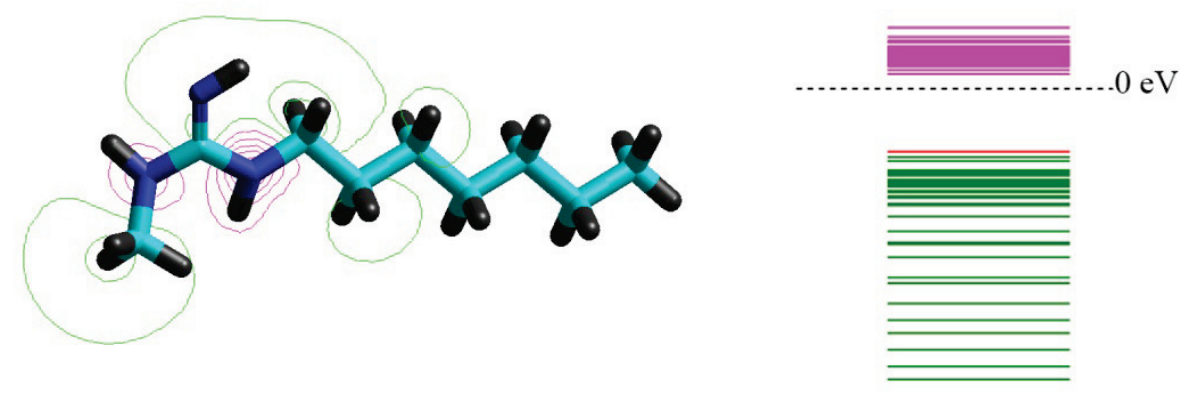

a
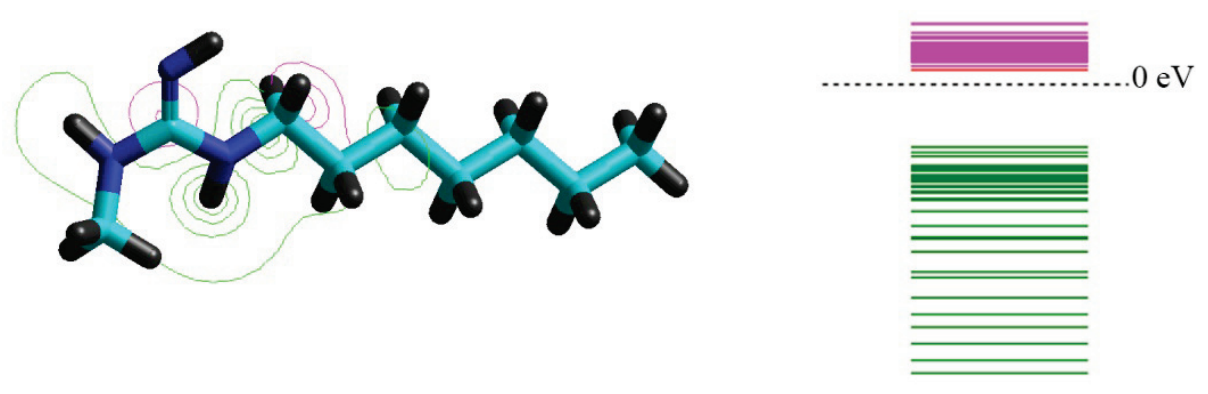

$\mathrm{b}$

Fig. 8. Distribution of UFMO energy (a) and LVMO energy (b) in the optimized model of monomer of polyhexamethylene guanidine hydrochloride (PHMG-HC).

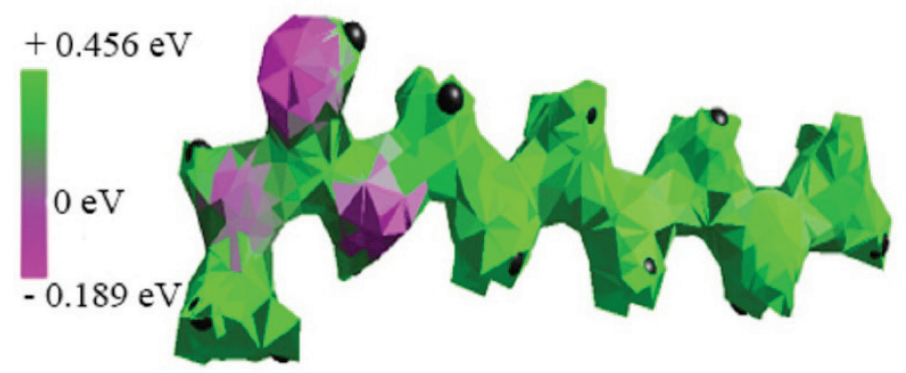

a

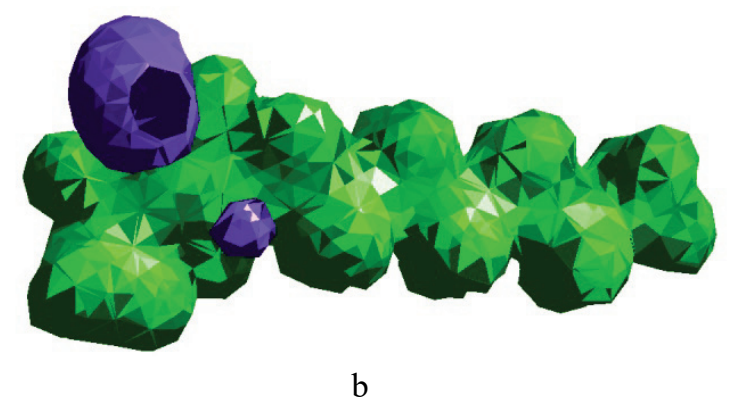

Fig. 9. Distribution of electrostatic potential in the optimized model of monomer of polyhexamethylene guanidine hydrochloride molecule (PHMG-HC) (a) and isosurface (b). 
Thus, the interaction with the fiber surface will have the following schematic structure represented in Figure 10.

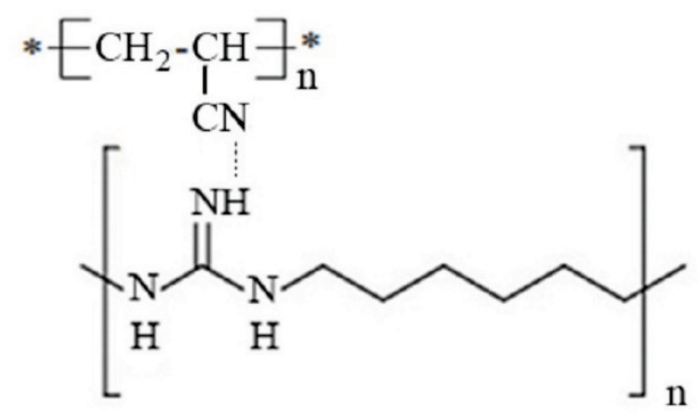

Fig. 10. Interaction scheme of ultrafiltration membrane and polyhexamethylene guanidine hydrochloride (PHMG-HC).

\subsection{Quantum-chemical researches of aluminum oxychloride}

As the main component for modification of ultrafiltration membrane, aluminium oxychloride $\mathrm{Al}_{2}(\mathrm{OH})_{5} \mathrm{Cl}$ is used. It should be mentioned that at the insertion into water solution oxychloride compounds $\mathrm{Al}(\mathrm{OH})_{\mathrm{m}} \mathrm{Cl}_{\mathrm{n}-\mathrm{m}}$ enter the hydrolysis reaction, the mechanism of which is expressed by the chemical equation (1) and lies in the interaction of complex ion of aluminum and chlorine with water molecules.

$$
\mathrm{Al}_{2}(\mathrm{OH})_{5} \mathrm{Cl}_{\mathrm{kp}}+\mathrm{H}_{2} \mathrm{O}_{\text {aq }}=2 \mathrm{Al}(\mathrm{OH})_{3} \text {, amorph }+\mathrm{HCl}_{\text {aq }} \text {. }
$$

Depending on the composition of the aquatic environment, the process of water molecules dissociation can be represented as an equation (2). Herewith, the increase in concentration either hydroxide ions or hydroxonium ions is observed.

$$
\mathrm{H}_{2} \mathrm{O}+\mathrm{H}_{2} \mathrm{O}=\mathrm{OH}+\mathrm{H}_{3} \mathrm{O}^{+} .
$$

The hydrolysis of aluminium oxychloride can be put down both as an equation (3) and equation (4)

$$
\begin{aligned}
& \mathrm{Al}_{2}(\mathrm{OH})_{5} \mathrm{Cl}_{\mathrm{kp}}+\mathrm{H}_{2} \mathrm{O}_{\mathrm{aq}}=2 \mathrm{Al}(\mathrm{OH})_{3}, \text { amorph }_{\text {aq }}+\mathrm{H}_{\mathrm{aq}}^{+}+\mathrm{Cl}_{\mathrm{aq}}, \\
& \mathrm{Al}_{2}(\mathrm{OH})_{5} \mathrm{Cl}_{\mathrm{kp}}+\mathrm{OH}_{\mathrm{aq}}=2 \mathrm{Al}(\mathrm{OH})_{3}, \text {, amorph }_{\text {aq }}+\mathrm{Cl}_{\mathrm{aq}}
\end{aligned}
$$

Figure 11 represents the optimized model of monomer of aluminium oxychloride molecule, the symbols of atoms and charges on atoms. Figure 12 represents the distribution of energy UFMO and LVMO in the optimized model of monomer of aluminium oxychloride molecule. Figure 13 represents the scheme of interaction of ultrafiltration membrane with aluminium oxychloride.

Thus, for the theoretical estimation of adsorptive capacity, it is appropriate to calculate

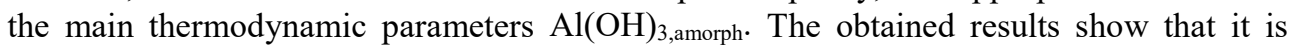


more probable that inorganic modifier $\mathrm{Al}(\mathrm{OH})_{3, \text { amorph }}$ is kept near the surface under the influence of ionic gravity.

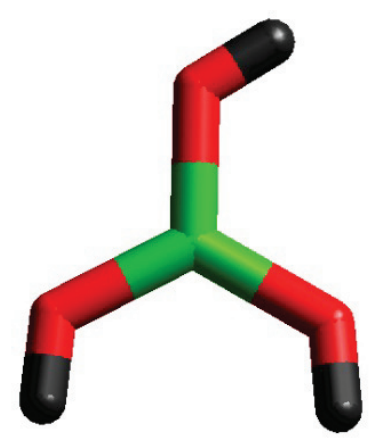

a

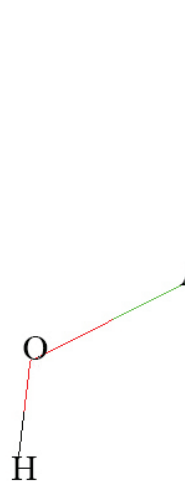

Al
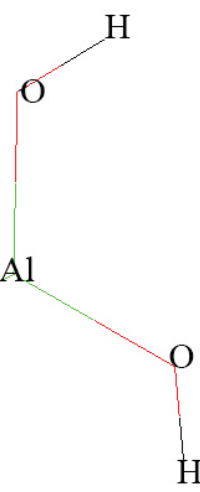

$\mathrm{b}$

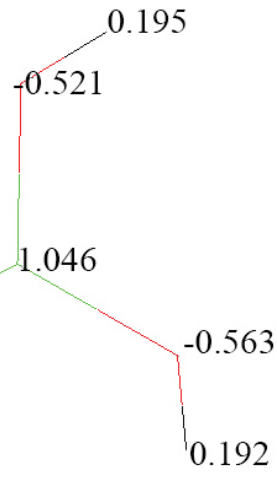

$\mathrm{c}$

Fig. 11. Optimized model of monomer of aluminium oxychloride molecule (a), the symbols of atoms (b) and charges on atoms (c).

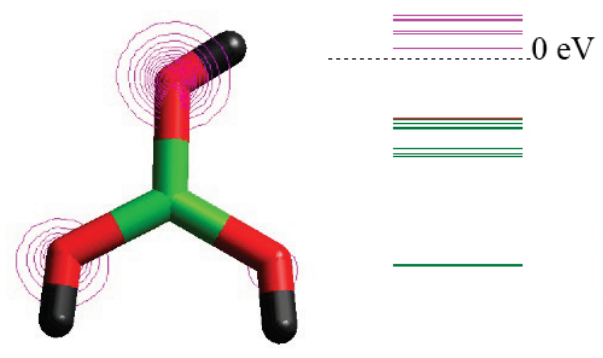

a

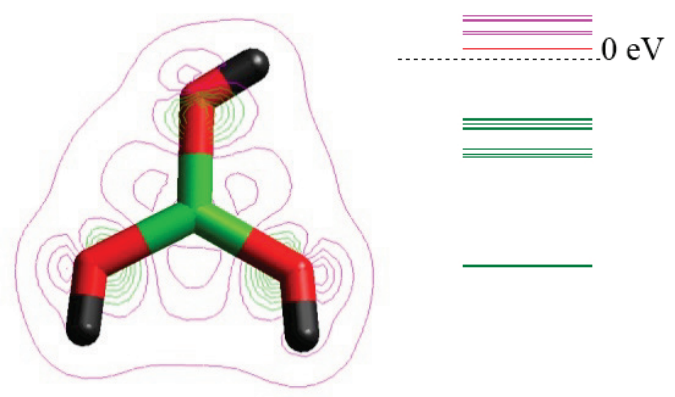

b

Fig. 12. Distribution of energy UFMO (a) and LVMO (b) in the optimized model of monomer of aluminium oxychloride molecule.
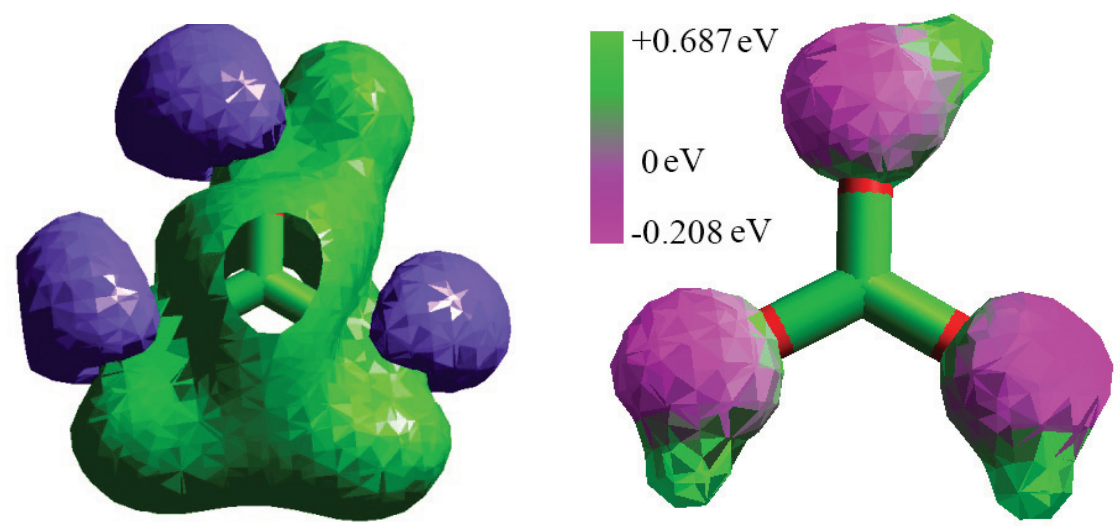

Fig. 13. Scheme of interaction of ultrafiltration membrane with aluminium oxychloride. 
Modification with aluminium oxychloride and polyhexamethylene guanidine hydrochloride with fiber surface will have the following schematic structure, represented in Figure 14.

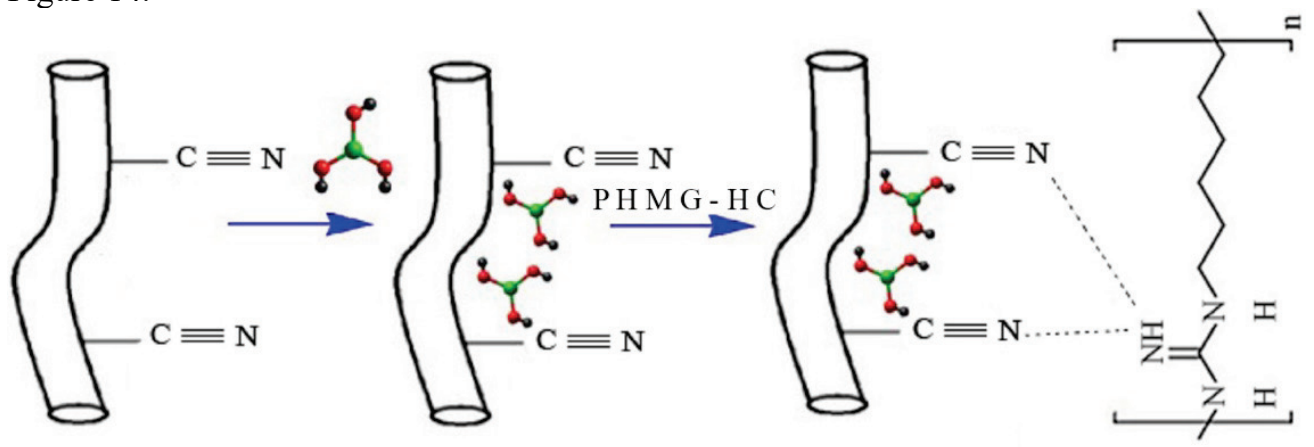

Fig. 14. Modification scheme of ultrafiltration membrane with aluminium oxychloride and polyhexamethylene guanidine hydrochloride (PHMG-HC).

\section{Conclusions}

The analysis of theoretical estimation and the grounding of the supposed mechanism of physicochemical surface modification by the estimation of reaction capacity of structural fiber component (monomer-polyacrylonitrile) and components of modifiers allow us to conclude that at the first stage of the modification of fiber surface at the insertion of aluminium oxychloride concretion $\mathrm{Al}(\mathrm{OH})_{3 \text {,amorpf }}$ on the membrane occurs, which are kept on the surface due to the Van der Waals dispersion forces. At the further stage, at the insertion of PHMG-HC, fiber functionalization is supposed to occur through the formation of hydrogen type bond between groups $-\mathrm{C} \equiv \mathrm{N}$ polymer and $=\mathrm{N}-\mathrm{H}$ group PHMG-HC.

\section{References}

1. Slastunov, S.V, Koroleva, V.N., Kolikov, K.S. (2001). Gornoe delo i okruzhayuschaya sreda. Moskva: Logos

2. Pevzner, M.E., Malyishev, L.A., Melkov, A.D., Ushan, V.P. (2001). Gornoe delo i ohrana okruzhayuschey sredyi. Moskva: Izdatelstvo Moskovskogo gosudarstvennogo gornogo universiteta

3. Dorozhko, S., Malkevich, N., Morzak, G. (2012). Tehnicheskie osnovyi ohranyi okruzhayuschey sredyi. Minsk: BNTU

4. Nechitaylo, N., Nagornaya, E., Nesterova, E. (2016). Exploring the properties of ultrafiltration membranes with a dynamic layer and bactericidal inoculation for the purification of natural waters. Vostochno-Evropeyskiy zhurnal peredovykh tekhnologiy [Eastern-European Journal of Enterprise Technologies], 6/5 (84), 46-53. https://doi.org/10.15587/1729-4061.2016.86187

5. Nechytailo, N., Nahorna, O., Kosiuk, Y. Defining the effect of the chemical concentration and solution $\mathrm{pH}$ on membrane chemical cleaning process. E3S Web of Conferences: International Conference Essays of Mining Science and Practice, 109 (2019). https://doi.org/10.1051/e3sconf/201910900061

6. Yu, X., Yi, B., Xie, Z., Wang, X., Liu, F. Prediction of the conformational property for polymers using quantum chemical descriptors. Chemometrics and Intelligent Laboratory Systems, 87(2), 247-251, (2007). https://doi.org/10.1016/j.chemolab. 


\subsubsection{1}

7. Liu, W., Yi, P., Tang, Z. QSPR Models for Various Properties of Polymethacrylates Based on Quantum Chemical Descriptors. QSAR \& Combinatorial Science, 25(10), 936-943, (2006). https://doi.org/10.1002/qsar.200510177

8. Bureau, C., Chong, D., Lécayon, G., Delhalle, J. Accurate density functional calculation of core electron binding energies. Journal of Electron Spectroscopy and Related Phenomena, 83(2-3), 227-234, (1997). https://doi.org/10.1016/S0368-2048(96)03096-4

9. Naves de Brito, A., Svensson, S., Ågren, H., Delhalle, J. Experimental and theoretical study of the XPS core levels of gas phase acetonitrile, acrylonitrile and propionitrile. Model molecules for polyacrylonitrile. Journal of Electron Spectroscopy and Related Phenomena, 63(3), 239-251, (1993). https://doi.org/10.1016/0368-2048(93)87006-L

10. Yu, X., Yi, B., Wang, X. Prediction of refractive index of vinyl polymers by using density functional theory. Journal of Computational Chemistry, 28(14), 2336-2341, (2007). https://doi.org/10.1002/jcc.20752

11. Xu, J., Chen, B., Zhang, Q., Guo, B. Prediction of refractive indices of linear polymers by a four-descriptor QSPR model. Polymer, 45(26), 8651-8659, (2004). https://doi.org/10.1016/j.polymer.2004.10.057

12. Yang, C., Wang, B., Zhang, Y., Wang, H. Preparation and properties of polyacrylonitrile fibers with guanidine groups. Fibers and Polymers, 16(8), 1611-1617, (2015). https://doi.org/10.1007/s12221-015-4480-1

13. Mei, Y., Yao, C., Fan, K., Li, X. Surface modification of polyacrylonitrile nanofibrous membranes with superior antibacterial and easy-cleaning properties through hydrophilic flexible spacers. Journal of Membrane Science, 417-418, 20-27, (2012). https://doi.org/10.1016/j.memsci.2012.06.021

14. Salaneck, W. R., Wu, C. R., Brédas, J. L., Ritsko, J. J. Electronic structure of polyacrylonitrile. Chemical Physics Letters, 127(1), 88-92, (1986). https://doi.org/10.1016/S0009-2614(86)80214-7 